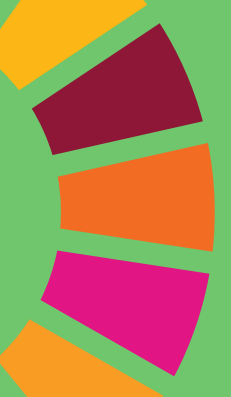

\title{
DE RENTAS MINIMAS A RENTA BÁSICA
}

\section{FROM MINIMUM INCOME TO BASIC INCOME}

\author{
Juan A. Gimeno \\ Universidad Nacional de Educación a Distancia (UNED) \\ jgimeno@cee.uned.es
}

Fecha recepción artículo: 27/06/2019 • Fecha aprobación: 02/08/2019

\section{RESUMEN}

El objetivo de asegurar una digna calidad de vida a toda la ciudadanía se intenta conseguir a través de diversos programas de garantías de rentas o de rentas mínimas. El sistema actualmente vigente en España es calificado unánimemente como deficiente por complejo, heterogéneo, ineficaz y burocrático; produce retrasos en las percepciones, induce la trampa de la pobreza, estigmatiza a los perceptores y no llega a la mayor parte de sus destinatarios. La renta básica supera claramente todos esos problemas. No se ignora que puede tener otros que, salvo el financiero, se analizan también en el artículo. Se concluye que una renta automática e incondicionada que favoreciera fundamentalmente a las personas de menores recursos y en riesgo de exclusión social, y, de forma decreciente, al resto de la población, es una política más eficaz y eficiente para luchar contra la pobreza que la maraña de políticas existentes.

Palabras Clave: rentas mínimas, renta básica, pobreza, renta mínima automática, garantía de ingresos.

\section{ABSTRACT}

The objective of ensuring a decent quality of life for all citizens is sought through various programs of income guarantees or minimum income. The system currently in force in Spain is unanimously qualified as deficient by complex, heterogeneous, inefficient and bureaucratic; it produces delays in perceptions, induces the trap of poverty, stigmatizes the perceivers and does not reach most of its potencial recipients. The basic income clearly exceeds all these problems. It is not ignored that it can have others that, except the financial one, are also analyzed in the article. It is concluded that an automatic and unconditional rent that favored fundamentally the people with fewer resources and at risk of social exclusion, and, in a decreasing way, to the rest of the population, is an more effective and efficient policy to fight against poverty than the tangle of existing policies.

Keywords: Minimum income, basic income, poverty, automatic minimum income, guarantee of income.

Juan A. Gimeno estudió Ciencias Económicas y Empresariales y Derecho, en la Universidad Complutense de Madrid, en la que se doctoró con premio extraordinario y en la que inició su carrera docente. Catedrático de Economía Aplicada desde 1986 en la UNED, universidad de la que fue Rector. Premios de investigación del Instituto de Estudios Fiscales y del CES. Primer director de la Revista Española del Tercer Sector. Fundador y patrono de Economistas sin Fronteras. 


\section{CONCEPTO Y NECESIDAD}

Los programas de rentas mínimas consisten en prestaciones económicas que buscan garantizar que toda persona cuente con ingresos suficientes para vivir dignamente, al menos en niveles de subsistencia. Normalmente, no exigen cotización previa, por lo que se denominan asistenciales, frente a las contributivas. Son prestaciones condicionadas a la demostración tanto de situación de necesidad del potencial beneficiario (o/y de su familia) como de esfuerzos activos por encontrar trabajo, de una forma u otra. Tradicionalmente, aunque empieza a graduarse, estas rentas son incompatibles con otros ingresos.

Estas prestaciones tienen un amplio respaldo en la Constitución Española.

- Ya en su preámbulo "proclama su voluntad de promover el progreso de la cultura y de la economía para asegurar a todos una digna calidad de vida".

- El artículo 41 señala que "Los poderes públicos mantendrán un régimen público de Seguridad Social para todos los ciudadanos, que garantice la asistencia y prestaciones sociales suficientes ante situaciones de necesidad, especialmente en caso de desempleo."

- El artículo 50, "Los poderes públicos garantizarán, mediante pensiones adecuadas y periódicamente actualizadas, la suficiencia económica a los ciudadanos durante la tercera edad."

Es evidente que el objetivo de un programa de rentas mínimas es luchar contra la pobreza, lo que las incardina con el primero de los Objetivos de Desarrollo Sostenible (ODS). En concreto, por ejemplo, sus metas 1.2 y 1.3 son:

- Para 2030, reducir al menos a la mitad la proporción de hombres, mujeres y niños de todas las edades que viven en la pobreza en todas sus dimensiones con arreglo a las definiciones nacionales.

- Poner en práctica a nivel nacional sistemas y medidas apropiadas de protección social para todos, incluidos niveles mínimos, y, para 2030, lograr una amplia cobertura de los pobres y los vulnerables

Según el Informe AROPE sobre el Estado de la pobreza en España (Llano Ortiz, 2018), en el año 2017, un total de 12.338.187 personas, el 26,6 \% de la población residente en España, está en Riesgo de Pobreza y/o Exclusión Social. Y el 5,1\% (más de 2,3 millones de personas) padecen pobreza severa, es decir, subsiste con menos de 342 euros al mes. Para la población menor de 16 años la tasa AROPE es del 31 \%: casi uno de cada tres menores está en riesgo de pobreza y/o exclusión social.

España está lejos de recuperar los datos previos a la crisis, y más aún de cumplir el objetivo de reducción de pobreza Europa 2020: necesitaríamos reducir en 2,3 millones el número de personas en riesgo de pobreza y/o exclusión social para esa fecha.

Estos datos muestran la necesidad de políticas de lucha contra la pobreza para ser coherentes con los principios constitucionales y con los compromisos asumidos a nivel mundial y europeo. Estos datos adelantan también la constatación de que las políticas actuales distan de ser eficaces. 


\section{UN CONSENSO CRECIENTE}

En realidad, la historia nos muestra que, implícitamente, nuestra sociedad ha ido aceptando la necesidad de garantizar unos ingresos mínimos a las personas que pasan por situaciones de especial necesidad.

Se parte de la idea de que la mayoría de las personas obtienen los medios que necesitan a través del trabajo y el salario que por él reciben. Pero cuando llega la jubilación, nos damos cuenta de que esas personas dejan de percibir ingresos y hay que cubrir sus mínimos vitales. Se monta así un sistema de contribuciones que dan derecho a la pensión futura. Y cuando lo cotizado es insuficiente para una pensión digna, se añade un complemento a mínimos. Y si no se percibe pensión por ausencia o insuficiencia de cotización, se arbitra una pensión asistencial para quien se encuentre en situación de necesidad. De alguna forma tenemos un sistema que ya garantiza, al menos teóricamente, una renta mínima para los mayores.

Lo mismo ocurre con los parados. Se instaura un subsidio de desempleo para quienes pierden su trabajo, se supone que para el corto periodo en que se tarda en encontrar otro. Para los parados de larga duración que se quedan sin derecho al subsidio anterior, se arbitra otro subsidio extraordinario por un plazo de tiempo, o uno asistencial cuando la necesidad es obvia.

Es decir, que tenemos admitida de hecho, una renta mínima universal para mayores y para buena parte de los parados. Aunque en la actualidad, desgraciadamente, un 40\% queda fuera de la prestación’.

De alguna forma, la parte esencial del sistema de garantía de ingresos mínimos sigue presuponiendo que el pleno empleo es lo normal y que solo hace falta buscar solución para jubilados y desempleados.

De entrada, esa presunción perjudica a las mujeres - tradicionalmente excluidas en mayor medida del mercado laboral -, a los niños - en un país como España que se sitúa a la cola en ayudas familiares - y a los jóvenes que no consiguen acceder al mercado de trabajo.

Cuando el desempleo lleva décadas por encima del $8 \%$ y, en la última, entre el 15 y el 20\%, porcentaje que se dobla para los jóvenes, la presunción de pleno empleo resulta especialmente engañosa.

Esta circunstancia parece agravarse con el desarrollo tecnológico. Ya es un lugar común hablar del paro que creará la robotización de la economía. Este temor acompaña a todas las revoluciones tecnológicas y la historia dice que al final el sistema se acaba adaptando. Es previsible que así sea... a largo plazo. Y a largo plazo, ya se sabe, todos muertos. Es preciso buscar soluciones a corto plazo para todo ese conjunto de personas excluidas del mercado de trabajo.

Por otro lado, parece observarse que el proceso está llevando a una creciente desigualdad y segmentación del empleo: una parte de trabajadores cualificados con estabilidad y buenos ingresos. Y otra parte condenada a la precarización, los contratos sin derechos laborales, los bajos ingresos... en suma, a la pobreza. Porque el empleo ya no es garantía de salir de la exclusión (V., por ejemplo, Comisión Europea 2019). En este informe, la Comisión Europea subraya que los cambios que la economía digital está provocando en los mercados de trabajo obligan a desligar las políticas tradicionales de subsidios del viejo concepto de empleo estable.

${ }^{1}$ En febrero de 2019, solo seis de cada diez parados percibían una prestación por desempleo. Del total de beneficiarios de prestaciones por desempleo: 822.782 eran perceptores de la prestación contributiva, 822.235, del subsidio; 150.900, de la renta activa de inserción; 102.127, del subsidio de eventuales agrarios, y 325, del extinto programa de activación para el empleo (PAE) 
No es de extrañar que esta evolución haya propiciado que cada vez en más foros, desde Davos a Silicon Valley, desde el Consejo de Europa al FMI- Fondo Monetario Internacional, vengan a pedir la implantación de una renta básica universal que garantice un mínimo vital, antes de que el descontento social se convierta en una bomba de relojería.

La manifiesta insuficiencia de los programas de garantía de ingresos descritos, ha llevado a la sucesiva aparición de programas complementarios de todo tipo, a menudo "electoralistas". Los más generales son los que se han ido arbitrando en las Comunidades Autónomas, de rentas mínimas con carácter general, aunque con regulaciones y cuantías diferentes. Incluso con denominaciones diversas y confusas² ${ }^{2}$ ya normativamente, ya en los debates públicos.

Este amplio y disperso panorama de programas merecerá su crítica más adelante, pero muestra cómo se viene caminando, de forma progresiva, hacia una renta mínima universal garantizada a cualquier persona en situación de necesidad. Eso sí, hasta el momento, condicionada y burocrática.

Esa evolución se refleja asimismo en el creciente consenso social en torno a la necesidad de esta garantía de ingresos mínimos. La figura 1 muestra que, de media europea, más de la mitad de la población es favorable a una renta básica. Y el porcentaje crece hasta acercarse al 70\% en favor de una renta mínima condicionada a bajos ingresos. En España, los resultados son más diferenciados: casi un ¡90\%! apoya la renta mínima, aunque queda levemente por debajo del $50 \%$ la posición favorable a la renta básica.

Es obvio que hay que tomarse con cautela estos resultados. Por un lado, porque la experiencia muestra que el apoyo se reduce cuando se coloca al lado el coste fiscal que podría acarrear la figura. Por otro lado, porque es generalizada la confusión terminológica y no todo el mundo diferencia entre rentas mínimas y renta básica de forma adecuada. Obsérvese (figura 2) que, en España, más de la mitad de los favorables a la renta básica se muestran partidarios de que se circunscriba a las rentas más bajas en tanto por ciento superior incluso al observado para la población total. No obstante, esta aparente contradicción puede no serlo tanto.

Curiosamente, no llega al 50\% (ni en España ni en la media europea) el porcentaje que apoya que las prestaciones económicas sean solo para las personas con rentas más bajas. Podemos concluir, razonablemente, que parece existir un consenso elevado en favor de un sistema que garantice ingresos mínimos a la población que lo necesite. Pero que ese consenso ya no es tan claro cuando hablamos de implantar una renta básica.

\footnotetext{
${ }^{2}$ Algunas denominaciones utilizadas: Ayudas para la Integración en Situaciones de Emergencia Social, Ingreso de Inserción, Ingreso de Integración, Ingreso Mínimo, Ingreso Mínimo de Inserción, Ingreso Mínimo de Inserción Social, Ingreso Mínimo de Solidaridad, Ingreso Mínimo Vital, Prestación Básica Familiar, Prestación de Inserción, Renta Básica de Inserción, Renta Básica Social, Renta de Ciudadanía, Renta de Garantía De Ingresos, Renta de Inclusión, Renta de Inclusión Social, Renta de Inserción, Renta de Integración Social, Renta Garantizada de Ciudadanía, Renta Garantizada Social, Renta Mínima de Inserción, Renta Social Básica, Salario Social Básico...
} 
FIGURA 1. PORCENTAJE DE POBLACIÓN EN FAVOR DE CADA OPCIÓN

En \%

Renta básica universal

- Renta mínima condicionada a bajos ingresos

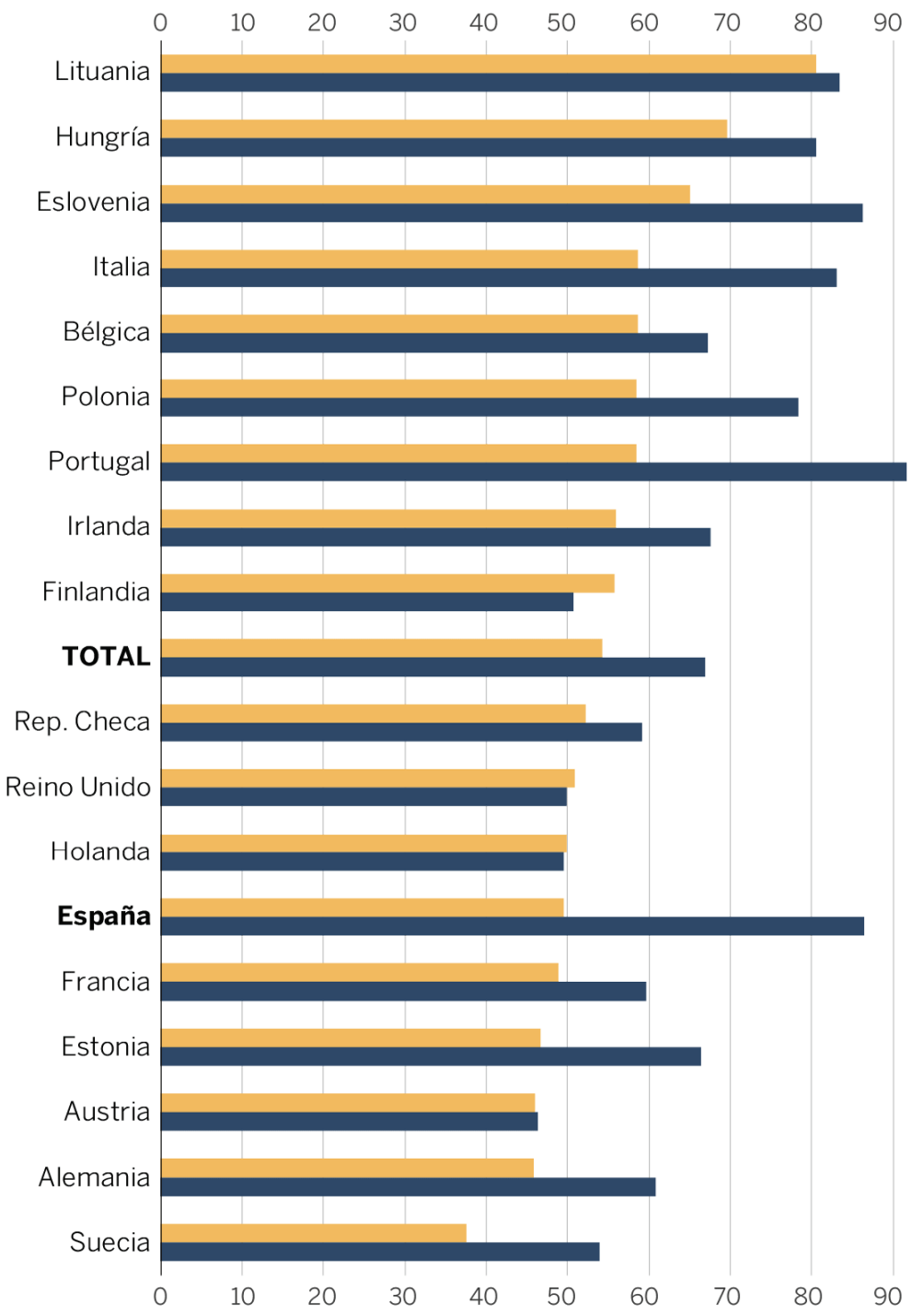


FIGURA 2. PORCENTAJE DE POBLACIÓN QUE APOYA QUE LAS PRESTACIONES ECONÓMICAS SEAN SOLO PARA LAS PERSONAS CON RENTAS MÁS BAJAS

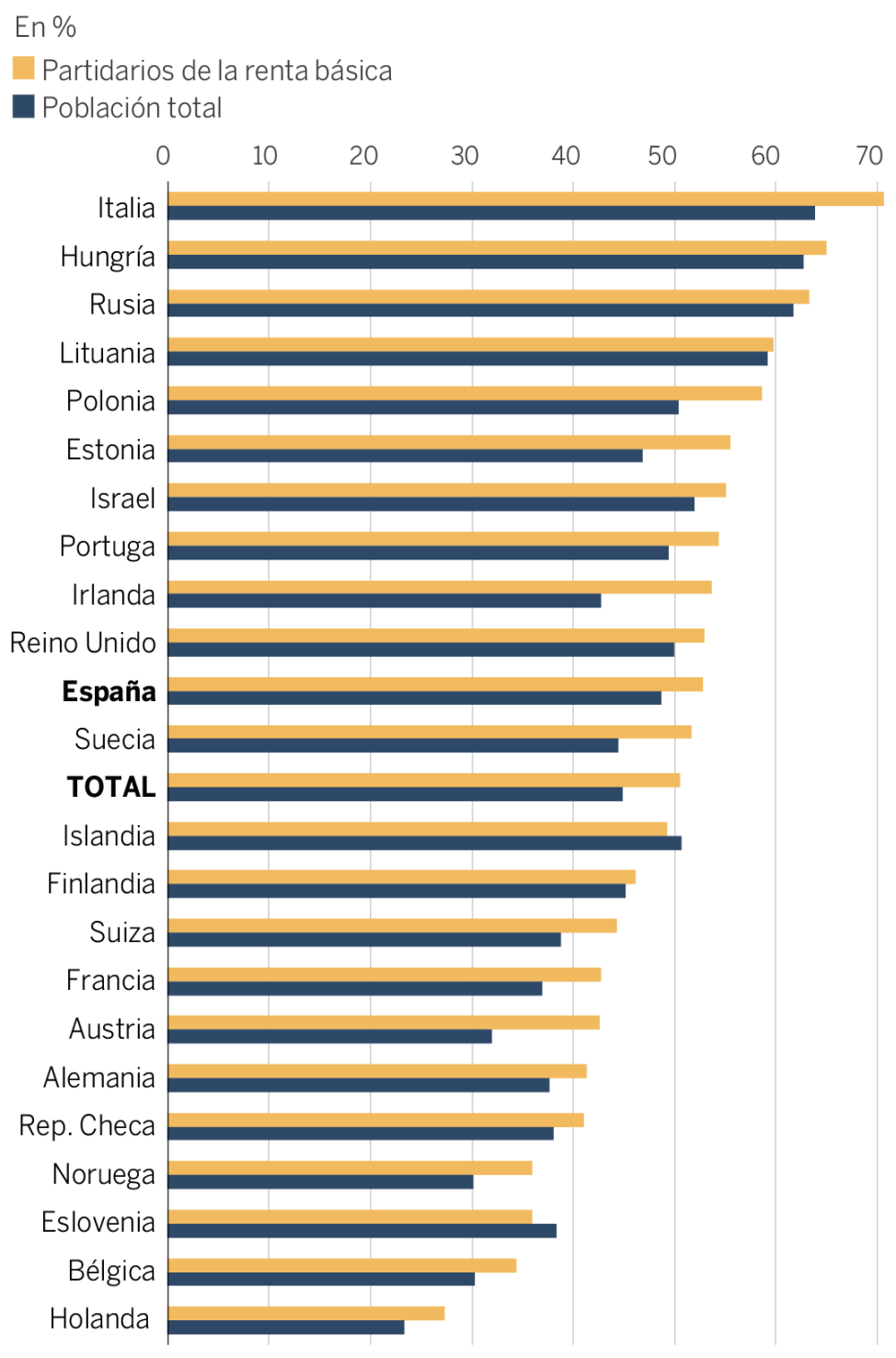




\section{DEFICIENCIAS DE LOS SISTEMAS VIGENTES DE RENTAS MÍNIMAS}

\subsection{COMPLEJIDAD Y HETEROGENEIDAD}

Los analistas de los sistemas españoles de garantías de ingresos coinciden en que el sistema de mantenimiento de rentas está formado por una maraña de programas, orientados a distintos grupos de población, cuya fragmentación y descoordinación se traduce en ausencia de criterios distributivos homogéneos. El sistema de prestaciones existentes resultante es complejo, heterogéneo y escasamente eficaz.

El ámbito de la Administración General del Estado (AGE), como resume, por ejemplo, Luis Sanzo (2018) "a lo largo de los años ochenta, y culminando en 1990 con la legislación sobre prestaciones no contributivas, la AGE desarrolló ese modelo asistencial, destinado a proteger a quienes queden fuera del sistema contributivo general, tanto en el ámbito de la atención a la invalidez o la jubilación como, de forma más específica, en el del desempleo. Los tres pilares del modelo, luego adaptado tras la aprobación del sistema de atención a la dependencia, son las siguientes prestaciones: el subsidio asistencial de desempleo, acompañado de la creación del subsidio o renta agraria; el subsidio de garantía de ingresos mínimos de la Ley de Integración Social del Minusválido (LISMI) y las pensiones no contributivas (PNC) por invalidez y jubilación. Estas actuaciones venían a unirse a los complementos de mínimos, a las pensiones contributivas y a las prestaciones por hijo a cargo para consolidar un sistema aparentemente muy amplio de protección, complementario al sistema contributivo general de la Seguridad Social y de protección al desempleo."

En 2000 se introduce la denominada renta activa de inserción, como un programa temporal para la inserción laboral de trabajadores desempleados de larga duración, en situación de necesidad y mayores de 45 años. La crisis financiera de 2008 obligaría a diseñar un nuevo tipo de actuaciones: el Prodi, el Programa de Recualificación Profesional (Prepara) y el PAE.

"En la actualidad, - prosigue Sanzo - en la dimensión relacionada con la protección al desempleo el modelo de subsidios asistenciales de la AGE fija, desde una primera lógica de intervención ordinaria, ciertos supuestos en los que se considera conveniente cubrir la ausencia de protección contributiva: fin de la protección en personas con alguna experiencia de cotización; población trabajadora agraria de Extremadura y Andalucía; personas en edades cercanas a la jubilación; población con responsabilidades familiares; y algunos colectivos especiales, tales como la población emigrante retornada, la excarcelada o la afectada por problemas de violencia de género.

En una lógica complementaria, ya sea en relación con colectivos con dificultades estructurales de acceso al empleo (RAI) o en situaciones que se siguen valorando como coyunturales pero que se mantienen a lo largo del tiempo, dada la situación de crisis (PAE en la actualidad), el sistema AGE trata de afrontar supuestos especialmente problemáticos. Éstos se ligan a determinadas circunstancias personales que pueden requerir un apoyo a largo plazo (violencia de género, presencia de discapacidad, ciertos colectivos de mayores de 45 años) o, de forma excepcional, a emergencias asociadas a un desempleo que se prolonga más allá de lo esperado."

Por su parte, ante las insuficiencias y lagunas del sistema estatal, las Comunidades Autónomas establecen sus programas de garantía de ingresos, con la variada denominación que se ha citado. Cada Comunidad Autónoma establece para sus beneficiarios los requisitos de acceso, cuantía, duración, etc. Como regla general se exige el empadronamiento con cierta antigüedad en el territorio de la Comunidad 
Autónoma; carecer de recursos económicos suficientes para las necesidades básicas de la vida; haber agotado ya el acceso a todas las ayudas a las que se pudiera acudir; y aceptar las medidas de inserción laboral que se le propongan³.

El simple relato anterior, aún sintético e incompleto, refleja un avance a saltos con la resultante complejidad y heterogeneidad que mencionábamos.

EI CES (2017, pág. 94 y ss.) resume muy bien la situación:

"La aproximación a los distintos instrumentos de garantía de ingresos mínimos en vigor permite afirmar la inexistencia en nuestro país de un sistema propiamente dicho de garantía de rentas mínimas en situaciones de carencia o insuficiencia de recursos. Ello responde a la manera en que históricamente se han ido creando las distintas ramas de la protección, alrededor de la noción de "riesgo" ... En las pensiones y prestaciones de naturaleza no contributiva, el principal hecho causante es el mismo que da origen a la contributiva, si bien se requiere, como requisito adicional, la demostración de carencia de recursos...

Esa propensión a categorizar los riesgos y el carácter subordinado de la pobreza conlleva la inevitable falta de adaptación a una realidad cambiante y la existencia de lagunas, en el momento en que surgen nuevos riesgos o variantes de los riesgos tradicionales que no estaban presentes en el momento de la configuración inicial de los derechos. Y cuando la pobreza se ha reconocido como un "riesgo" con entidad propia para ser protegido per se a través de transferencias económicas, lo ha hecho en el terreno de la asistencia social, competencia exclusiva de las CCAA, a través de un instrumento principal (las rentas mínimas) con características, alcance, enfoque y resultados muy heterogéneos.

La diversidad de prestaciones y ayudas configura una suma de transferencias económicas de distinta índole que alcanzan a más de cinco millones de situaciones de necesidad acreditadas en cada caso con arreglo a sus diferentes requisitos."

Sin menoscabo de reconocer el efecto positivo de buena parte de estos programas, por insuficiente que resulte, reúnen unas características (como las que se analizan a continuación) que los hacen manifiestamente mejorables.

\footnotetext{
${ }^{3}$ El Ministerio de Sanidad (Secretaría de Estado de Servicios Sociales e Igualdad, Dirección General de Servicios para las Familias y la Infancia) publica Informes anuales de rentas mínimas de Inserción. El último publicado (febrero 2019) se refiere al año 2017.
} 


\subsection{INEFICACIA}

Se supone que el objetivo principal de las rentas mínimas es el de eliminar o reducir la pobreza. Sin embargo, los estudios académicos sobre la efectividad de estos programas (v. Bollain y Raventós, 2019), muestran el escaso cumplimiento de dicho objetivo, tanto por los vaivenes de sus generalmente escasos presupuestos, como por las otras deficiencias que en seguida repasaremos.

\section{FIGURA 3. REDUCCIÓN DEL ÍNDICE DE GINI POR LAS PRESTACIONES MONETARIAS}

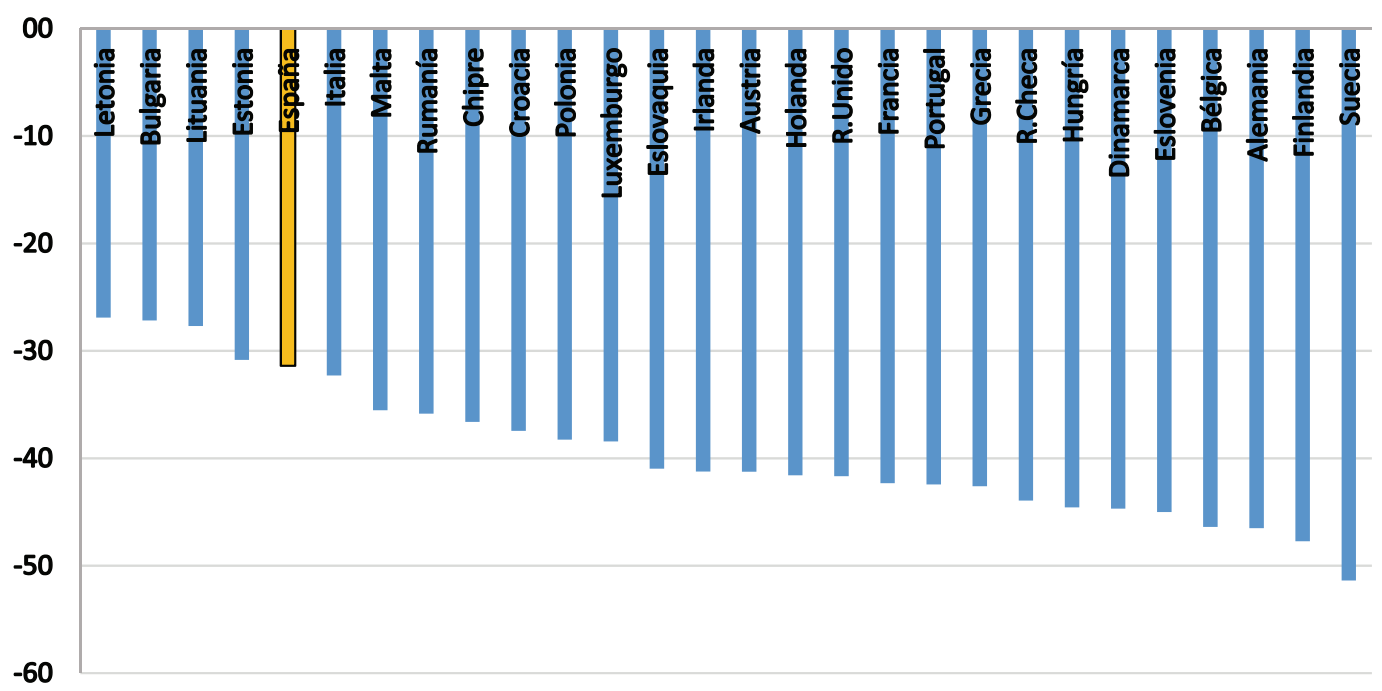

La evolución y heterogeneidad descritas poco más arriba contribuyen, sin duda, a esa carencia.

Los datos en España confirman esa tendencia. La escasa capacidad del sistema para reducir la desigualdad de las rentas primarias es notoria, muy inferior a la de otros países, incluso varios con una renta per cápita sensiblemente inferior a la española (Ayala y Gimeno, 2019 - figura 3).

\subsection{COSTES ADMINISTRATIVOS ELEVADOS}

Los costes de gestión de estos programas son muy altos, tanto para la administración pública como para el propio sujeto beneficiario, sometido a farragosos controles y trámites administrativos.

La simple existencia de múltiples programas ya exige una burocracia diversificada y una complejidad notoria para los posibles perceptores. La primera dificultad para las personas en estado de necesidad es saber si su caso está previsto y cuál es la ventanilla a que debe dirigirse.

El hecho de que todos los programas sean condicionados (a situación de pobreza y a otros requisitos específicos de cada programa) exige verificar que las personas solicitantes cumplen realmente con cuanto se prevé en la normativa concreta. Una vez superada la admisión y concedida la ayuda, se mantiene el control periódico de las condiciones, con especial atención a los ingresos de la unidad familiar beneficiaria, para comprobar que se mantiene la legitimidad de acceso. 
Es difícil estimar a cuánto ascienden estos costes. Bollain y Raventós (2019) calculan que pueden significar, como promedio, un $9 \%$ del presupuesto total de los programas.

Pero hay otros costes conexos que pueden resultar todavía más perjudiciales que el económico descrito. Por un lado, la enorme burocracia exigida distrae a los servicios sociales de su tarea más directa de atención a personas y colectivos necesitados. Frente a su misión y vocación de servicio, aparecen más como policías y perseguidores de los colectivos a quienes deben ayuda que como colectivo colaborador. Con la consiguiente frustración laboral y pérdida de eficacia de los propios servicios.

Por otro lado, la tarea de comprobación supone una invasión de la intimidad familiar incómoda y hasta potencialmente inconstitucional. Desde la solicitud hasta el fin de la prestación, se persigue cada detalle en la vida de todos y cada uno de los integrantes de la unidad familiar de forma agobiante.

Con razón, y este es otro de los costes indirectos, los estudios muestran que las barreras y controles burocráticos son una de las causas explicativas de que muchos de los posibles beneficiarios de este tipo de ayudas desistan de solicitarlas, o abandonen en el proceso correspondiente de acreditación de las condiciones.

\subsection{RETRASO EN EL DISFRUTE DE LA PRESTACIÓN}

Una lógica consecuencia de ese complejo proceso burocrático necesario para acceder a las prestaciones asistenciales y programas de rentas mínimas es el importante retraso que se produce desde el momento en que se inician los trámites de solicitud y el efectivo disfrute de la prestación, con el consiguiente efecto de desprotección temporal.

El Defensor del Pueblo de Andalucía denuncia los retrasos de ocho meses de media en el acceso y percepción de la Renta Mínima de Inserción. Los sucesivos informes de EAPN (Red europea contra la pobreza) coinciden en señalar retrasos medios de entre diez y doce meses en resolver las solicitudes presentadas, con casos no infrecuentes de retrasos de hasta dieciocho meses. Aunque los datos sean dispersos, la impresión general de los expertos y los sectores relacionados con estas prestaciones son coincidentes.

\subsection{TRAMPA DE LA POBREZA}

Como hemos visto, las prestaciones de garantía de rentas están condicionadas al cumplimiento de una serie de requisitos. El más habitual, es que sean incompatibles con la obtención de un empleo o de otros ingresos por cualquier vía.

Es evidente que tal condición supone un desincentivo al empleo y un estímulo a la economía sumergida. El fenómeno se ve agravado por el deterioro observado en el mercado laboral a lo largo de la última década. La precarización generalizada y el incremento de los denominados empleos basura, han llevado a que conseguir un empleo no sea ya condición suficiente para abandonar la pobreza.

Los perceptores de subsidios se encuentran así ante una situación en que aceptar una oferta de empleo puede conllevar un empeoramiento en su situación: no solo por las molestias inherentes a un trabajo (horarios rígidos, desplazamientos, esfuerzo), sino incluso en términos estrictamente monetarios.

La condicionalidad en los subsidios empuja a los beneficiarios a caer en la trampa de la pobreza, anclándose en el subsidio. Dado el desincentivo que perder la ayuda supone a la hora de aceptar ofertas de trabajo 
remunerado de baja cuantía o a tiempo parcial, es fácil que renuncien o que acepten incluso más fácilmente un empleo en la economía sumergida (que no les priva del subsidio) que en la regular.

Este efecto es tan evidente, que algunas regulaciones de rentas mínimas han comenzado a flexibilizar la incompatibilidad de forma gradual, aunque manifiestamente insuficiente. Cuando el subsidio simplemente complementa la diferencia entre el salario percibido y la cuantía de aquél en ausencia de trabajo, se mantiene el desincentivo. Aún más, parece estimularse la proliferación de ofertas basura.

\subsection{ESTIGMATIZACIÓN}

La práctica totalidad de las rentas de garantía de mínimos implican el reconocimiento público de situaciones de carencia absoluta de recursos, la acreditación del estado de marginación y exclusión social. Ello supone de hecho una estigmatización social, que se ve agravada con ese tipo de discurso que carga la culpa de la pobreza sobre las personas afectadas, tachadas de vagos, ignorantes, irresponsables... Los sistemas de control arbitrados implican en sí mismos una enorme desconfianza y una aparente presunción de culpabilidad hacia quien solicita el subsidio.

De hecho, esos mecanismos de control, como se señalaba más arriba, suponen una invasión desproporcionada por parte de las Administraciones Públicas en la intimidad y las vidas de las personas y sus familias.

La obligada situación de sometimiento y, al menos subjetivamente, humillación, contribuye a una mayor estigmatización de las personas solicitantes; especialmente en poblaciones de menor tamaño, donde el proceso es conocido fácilmente por el entorno de las familias afectadas. Como ahora veremos, este es un factor que empuja a muchos beneficiarios potenciales a desistir de entrar en esa rueda.

\subsection{BUENA PARTE DE LOS POSIBLES BENEFICIARIOS NO ACCEDEN A LAS AYUDAS}

Ya Laparra y Ayala (2009) señalaban, antes de la crisis, que los salarios sociales no llegaran más que a una de cada cinco familias de la demanda potencial, estimada en un cuarto de millón de hogares. El Informe sobre rentas mínimas de EAPN (Malgesini, 2014) recogía la opinión de los expertos que cifraba en casi un millón el número de personas vulnerables que quedaba fuera del sistema de protección. Estimaciones para la Comunidad de Madrid señalan que del total de 133.000 hogares que se encuentran en situación de pobreza severa, sólo 22.187 reciben la subvención dirigida a cubrir los mínimos vitales de una familia. Es decir, un 17\% de sus potenciales destinatarios.

De nuevo, a pesar de la dispersión de datos, hay una consciencia generalizada de que los programas existentes dejan fuera a la mayor parte de sus teóricos destinatarios. Probablemente, uno de los síntomas más sangrantes de que el sistema no funciona.

Las causas explicativas son muy diversas. Algunas ya se han ido adivinando en los puntos anteriores. Según la encuesta realizada por Malgesini (2014), las razones más presentes parecen las siguientes (ordenadas de mayor a menor porcentaje de apoyo):

- $67 \%$ - Debido a que no saben que tienen el derecho

- $61 \%$ - Debido a que no entienden los mecanismos para la presentación 
- 61\% - Debido a su situación de vida no les permite dar una dirección válida (falta de vivienda, viviendas de transición, los ocupantes...

- $44 \%$ - Debido a que la documentación es muy compleja y desisten de su presentación

- $33 \%$ - Debido a que el tiempo de espera es demasiado largo

- $28 \%$ - Debido a que no conocen los mecanismos para la presentación

- $28 \%$ - Debido a que asumen que no se la van a conceder

- $22 \%$ - Por miedo al estigma social

- $11 \%$ - Porque quieren conseguir un trabajo, no una renta baja y, por lo tanto, no la piden mientras siguen buscando otras opciones...

- $11 \%$ - Debido a que no pueden encontrar consejos prácticos

- $6 \%$ - Debido a que viven lejos de la oficina tramitadora y no pueden darse el lujo de viajar para cumplir con el procedimiento formal

- $6 \%$ - Debido a que no entienden el idioma lo suficientemente bien

- $6 \%$ - Debido a que tienen un bajo o nulo nivel de educación/formación

El informe señala que, además de estas posibles explicaciones, algunas respuestas apuntaron que los padres, en general, y los extranjeros que dieron a luz a los niños/as en España (los niños y niñas que potencialmente podrían adquirir la nacionalidad española), en particular, no solicitan las Rentas Mínimas porque tienen miedo de que los Servicios Sociales les quiten a sus hijos/as.

La conclusión parece clara. El sistema que tenemos de garantía de mínimos y lucha contra la pobreza hace aguas por todos lados. Resulta difícil no coincidir con Uribarri (2015): “...no ha fallado la gestión de un modelo de rentas mínimas garantizadas y condicionadas, ha fallado el modelo en sí. Quien no lo quiera ver... solo puede ser porque está guiado/a por el inmovilismo. Porque no quiere asumir que aceptar las críticas señaladas en este artículo obligan a un cambio de rumbo radical, a la búsqueda de otro modelo. Uno que se aparte de cualquier exigencia de condicionalidad, sobre todo que se desligue absolutamente del empleo, que establezca un nivel de renta garantizada con carácter universal y dotada con un importe superior al umbral de la pobreza, única forma de erradicar la misma. Ese es el modelo de quienes defendemos la Renta Básica Universal (RBU)".

\section{El SALTO A LA RENTA BÁSICA}

\subsection{UNA SOLUCIÓN GLOBALIZADORA}

El diagnóstico general es coincidente en detectar la complejidad e insuficiencia de nuestro actual "no sistema" de protección social.

El Consejo Económico y Social concluye, en su Informe sobre las Políticas públicas para combatir la pobreza en España lo siguiente: "A fin de visualizar mejor el conjunto de ayudas existentes, la elaboración del mapa 
completo de prestaciones sociales y subsidios de desempleo comprometido en el ámbito del diálogo social constituiría un primer paso de cara al cumplimiento del compromiso contemplado por la Ley 27/2011, de 1 de agosto, sobre Actualización, adecuación y modernización del Sistema de Seguridad Social, así como por el Plan Nacional de Inclusión Social 2013-2016 actualmente en vigor. Se trataría de abordar una reordenación integral de las prestaciones no contributivas de la Seguridad Social, con el objetivo de mejorar su cobertura, establecer con más claridad el ámbito de sus prestaciones e introducir nuevos ámbitos de protección en orden a colmar lagunas de cobertura que se detectan." (CES 2017, pág. 181)

Coincidiendo en el análisis, parece evidente que la reordenación integral de las prestaciones no contributivas no pasa por elaborar un mapa del caos existente e ir colmando lagunas para hacerlo cada día más complejo, burocrático e ineficiente.

En esa misma línea, debe reseñarse la tramitación en el Congreso de los Diputados español de la Ley de Iniciativa Legislativa Popular para establecer una Prestación de Ingresos Mínimos en el ámbito de protección de la Seguridad Social. La iniciativa, promovida por los sindicatos CCOO y UGT, se presentó el 19 de julio de 2016 y superó el 28 de septiembre de 2017 la enmienda a la totalidad presentada por el PP, al recibir 175 votos en contra de la enmienda frente a los 167 a favor.

La prestación se define como un derecho subjetivo, orientado a proteger a quienes se encuentran en edad laboral y queriendo trabajar carecen de empleo y de ingresos suficientes para garantizar un nivel de vida suficiente. La prestación, equivalente a una $80 \%$ del IPREM (es decir, a 426 euros al mes en el momento de presentarse), se percibe de forma indefinida mientras se cumplan los requisitos de acceso y se mantiene la situación de carencia de ingresos.

Se configura como prestación no contributiva de último recurso, en el ámbito de la Seguridad Social, con financiación estatal y con cargo a la imposición general.

Esta propuesta, indudablemente positiva, responde a aquel mismo esquema de análisis: rellenar lagunas del actual sistema y ligarlo al empleo.

Pero la revisión que nuestro sistema necesita no puede seguir anclada ni al empleo ni a situaciones específicas de necesidad.

La idea de ir generando una medida protectora para todas y cada una de las sucesivas situaciones de necesidad que vamos detectando supone repetir el mismo error que nos ha traído hasta aquí. Como se señalaba más arriba, hemos ido arbitrando un seguro para cada situación de riesgo. Y eso lleva inevitablemente a la complejidad, a la burocracia, a la ineficacia y a la ineficiencia.

Estaríamos en una situación equiparable a la de Sísifo: empujando perpetuamente un peñasco gigante montaña arriba hasta la cima, sólo para darnos cuenta de que hay que volver hasta el valle, para empujar una nueva piedra hasta la cumbre, y así indefinidamente. Porque siempre encontraremos lagunas no cubiertas, colectivos no asistidos, situaciones no previstas. A base de parches jamás lograremos cubrir la gama infinita de posibles situaciones personales y familiares.

La única forma de cubrir todos los supuestos de necesidad es diseñar una figura que, directamente, defina a sus beneficiarios de forma universal: solo una renta mínima universal garantiza la cobertura total. Obvio.

Pero tampoco podemos ligar la prestación al empleo según se ha hecho hasta ahora. De nuevo, por varias razones que, en buena medida han sido ya apuntadas más arriba. 
- Diseñar un sistema de protección tan solo para quienes no tienen acceso al empleo presupone una situación global, normal, de pleno empleo. ¿Qué ocurre cuando el pleno empleo se convierte en una característica extraordinaria en nuestra economía? Llevamos una década con niveles de paro oficial por encima del $15 \%$. Y en momentos considerados de gran expansión, el suelo de desempleo se situaba prácticamente en el $8 \%$.

En los próximos años, los pronósticos no son muy optimistas. El progreso de la inteligencia artificial, la robotización y una economía financiarizada y tecnológica amenazan con la destrucción de millones de puestos de trabajo tradicionales. Ya se ha señalado que una parte de los nuevos empleos que se crean requieren una especialización que no está al alcance de los desplazados de la "vieja economía". Y que buena parte de los empleos no especializados que se requieren tienen todas las características de trabajo basura, precarios, sin protección social, parciales y mal remunerados; trabajadores que con su empleo no consiguen salir de la situación de pobreza y exclusión social. El pronosticado equilibrio a largo plazo no nos exime de buscar protección en el corto plazo a quien tiene necesidad. Las políticas de garantía de rentas existen precisamente para corregir las situaciones existentes de exclusión social, mientras, idealmente, se solucionan los problemas estructurales que causan esas situaciones.

Más aún cuando ese nuevo equilibrio que se adivina promete una desigualdad mucho mayor que la que hemos conocido y una probable situación de pobreza creciente, afectando quizás a más de la mitad de la población.

Esa nueva perspectiva obliga a pensar en una renta garantizada universal... sin que ello suponga dejar de luchar por el pleno empleo y por un empleo digno para toda la población. Ni son ni pueden ser objetivos incompatibles.

- Diseñar un sistema de protección tan solo para quienes no tienen acceso al empleo supone, como se ha señalado, una discriminación para mujeres, niños y jóvenes. ¿Tendremos que montar programas especiales para mujeres, niños y jóvenes? ¿No es más sensato diseñar directamente un sistema de acceso universal?

- Por último, y no menos importante: ¿qué empleos consideramos? Porque en esa concepción dominante, la que liga prestaciones y empleo, solo tomamos en cuenta el trabajo remunerado, el que pasa por el mercado y se corresponde con una retribución. Ello supone ignorar muchísimas horas de trabajos no remunerados, que contribuyen sustancialmente al bienestar general e, incluso, son absolutamente imprescindibles para la reproducción del sistema. Todo el trabajo de cuidados, de generación y conservación de la vida; todos los trabajos de voluntariado, de trabajo desinteresado en favor de las más diversas causas; todas las tareas dedicadas a la creación artística al crecimiento personal, sin retribución monetaria...

Hay muchísimo trabajo que no mide el PIB, sin el cual el bienestar social sería no menor, sino imposible. Hay muchísimo trabajo que hay que reivindicar como tan importante y necesitado de valoración y protección como el convencionalmente considerado como tal.

Por todo ello, es necesaria efectivamente una reordenación integral de las prestaciones no contributivas de la Seguridad Social, como pide el CES. Pero solamente será eficaz, como señalaba Uribarri, si es universal, incondicionada y desligada del empleo. Es hora, pues, de hablar de la renta básica. 


\subsection{SUPERACIÓN DE LAS DEFICIENCIAS VIGENTES}

Es fácil comprobar que todas y cada una de las deficiencias señaladas en relación con el sistema de garantía de rentas imperante en España se solucionarían con un modelo de renta básica automática e incondicionada. Es decir, sustituir todas las prestaciones asistenciales y programas de garantía de rentas por una prestación automática e incondicional a cualquier persona ${ }^{4}$, sin requisitos previos ni incompatibilidad con otros ingresos.

- Frente a complejidad y heterogeneidad, unidad y simplicidad: todo el actual conjunto de medidas dispersas se sustituye por un único instrumento claro, transparente, sin requisitos, universal y uniforme.

- Frente a ineficacia, eficacia y eficiencia: el carácter universal garantiza la práctica solución de la pobreza extrema y un alivio importante - dependiendo, naturalmente, de su cuantía - de la pobreza relativa.

- Frente a costes administrativos elevados, burocracia mínima. Con carácter general, no es necesario presentar solicitud ni documentación acreditativa de condiciones inexistentes. Por el lado de la administración, tampoco es necesario dedicar recursos ni tiempo a verificación alguna ni a control o inspección. La gestión cotidiana se inscribe en el normal funcionamiento de la Seguridad Social. Serían necesarios algunos esfuerzos, sobre todo iniciales, para integrar a los colectivos en exclusión social extrema y, en ciertos casos, un reducido control del paso de la condición de menor a la de adulto y de no residente a residente. Y poco más.

- Frente al retraso en el disfrute de la prestación, automatismo. La renta básica no espera a que se produzca el estado de necesidad, sino que se adelanta y garantiza la prestación ex ante.

- Frente a la trampa de la pobreza, compatibilidad. La renta básica no se pierde por el hecho de percibir otros ingresos. Con ello, desaparece un importante desincentivo a aceptar ofertas de trabajo y es menor el atractivo del trabajo sumergido. Con un sistema de renta básica, el desincentivo al esfuerzo será siempre menor que con los sistemas actuales.

- Frente a estigmatización, derecho de ciudadanía. La renta básica no exige demostrar la situación de necesidad, no implica "desnudarse" ante el aparato administrativo, no necesita ninguna calificación. La renta básica es percibida por toda persona en situación de igualdad, sin distinción alguna de entrada. Es un derecho que puede recibirse con orgullo, sin sensación alguna de humillación social.

- Frente al hecho de que buena parte de los posibles beneficiarios no acceden a las ayudas, universalidad. Si examinamos los motivos explicativos de la situación de no acceso a las prestaciones aun existiendo el derecho, prácticamente todos ellos desaparecen (o se reducen sustancialmente) en un sistema con renta básica universal. Prácticamente, solo colectivos en grave situación de exclusión social podrían tener problemas de incorporación en el corto plazo. Probablemente, los servicios sociales, liberados de la actual burocracia de rentas mínimas, podrían reducir sustancialmente el número de personas afectadas por esa falta de cobertura. En todo caso, no cabe duda de que el porcentaje bajaría radicalmente.

Es obvio que no todo pueden ser ventajas y solo ventajas. Si así fuera, extrañaría no ver su generalizada aplicación. Veamos algunos de los inconvenientes que suelen aducirse para oponerse a la implantación de una renta básica.

\footnotetext{
${ }^{4}$ Naturalmente, cualquier persona que esté en el universo contemplado por la renta básica: normalmente adultos residentes (y menores, con cuantía de prestación más reducida).
} 


\subsection{EMPLEO Y SALARIOS}

¿Supondrá la percepción de una renta garantizada sin condiciones que buena parte de la población opte por salir del mercado de trabajo? La literatura que defiende el posible incentivo perverso de los subsidios de garantía de renta sustenta el razonamiento fundamentalmente en la ya mencionada trampa de la pobreza, por el hecho de que encontrar trabajo implica perder el subsidio.

Pero ya ha debido quedar claro que precisamente la renta básica elimina ese problema. Al no perderse la renta básica por la existencia de nuevos ingresos, estos resultan marginalmente más atractivos puesto que son adicionales y no alternativos. La experiencia muestra que la obtención de una renta no desestimula obtener ingresos adicionales. Las horas extraordinarias son un claro ejemplo. Por otro lado, una cuantía de renta básica en línea con las actuales de rentas asistenciales (en el entorno de los 450 euros mensuales para una persona adulta), difícilmente puede considerarse disuasoria y suficiente.

En el fondo, este mismo temor se ha manifestado de siempre en relación, por ejemplo, con los subsidios de desempleo. Desde la completa revisión de Danziger et al. (1981) a Ben-Shalom et al. (2011) o Muñoz de Bustillo y Antón (2013), constatanquenoexisteunacorrelación decisiva entre los diversos sistemas de prestaciones sociales y la oferta de trabajo, sino que hay que prestar atención a otros muchos factores económicos e institucionales.

Para estimar los efectos, podríamos también estudiar las conclusiones de las diversas experiencias realizadas en muy diversas zonas y con muy distintas condiciones, o citar los resultados de algunas simulaciones econométricas (v. Van Parijs y Vandervoght, 2017 pág. 190 y ss.). En unas y otros parece observarse una leve caída de participación en el mercado de trabajo y una reducción de promedio de horas trabajadas.

Hay que destacar que los modelos teóricos son más pesimistas en sus previsiones que las que se han observado en la realidad. Pero los datos más negativos se sitúan en un $5 \%$ de caída. En un país como el nuestro, casi estancado en el $15 \%$ de desempleo y que no ha bajado del $8 \%$ desde hace décadas, incluso ese impacto debería importarnos poco.

Los experimentos observados muestran un casi nulo efecto en el esfuerzo por parte de la población perceptora del subsidio. Sí se percibe con frecuencia alguna reducción en el tiempo de trabajo ofertado por algunas de las personas beneficiarias. Pero no hacia la vagancia, sino más bien hacia esos otros trabajos no remunerados que más arriba se mencionaban (cuidados, voluntariado...), no considerados por el mercado, pero de gran interés social.

En todo caso, es preciso relativizar los resultados obtenidos tanto de los experimentos como de las simulaciones teóricas. Las condiciones o las hipótesis adoptadas de inicio condicionan y contaminan los posibles resultados. Y nunca pueden considerarse garantía de coincidencia con una medida que pasaría a ser universal y no parcial, permanente y no temporal, real y no teórica.

¿Podría la renta básica provocar una reducción de salarios? Las empresas, conociendo que ya existe esa renta garantizada, podrán aprovechar para reducir los salarios en la confianza de que más trabajadores podrían aceptar esas ofertas. Es difícil predecir ese posible efecto. En principio, la experiencia parece mostrar que el trabajador subsidiado tiene más margen para ser selectivo y no aceptar trabajos especialmente poco adecuados o atractivos. Y, en negociaciones de condiciones laborales, la renta básica actúa como una caja de resistencia que puede potenciar la capacidad negociadora de los sindicatos. La existencia de un salario mínimo y, en su caso, una legislación laboral adecuada, pueden suponer un cuadro general poco propicio a que se produzca ese descenso temido de salarios. 
Precisamente se argumenta que la renta básica puede ser un instrumento eficaz contra la propia existencia de los "trabajo basura", pues quien percibe una renta básica puede más fácilmente exigir unas condiciones mínimas razonables. Por el lado opuesto, se teme que los trabajos desagradables o/y poco remunerados, lejos de desaparecer, pasarían a ser realizados por personas que no posean la ciudadanía, por quienes no puedan recibir el subsidio por cualquier motivo. Efectivamente, como veremos, una renta básica nunca podrá ser ni completamente universal ni absolutamente incondicionada. Las minorías excluidas seguirán probablemente en esta situación de riesgo de exclusión laboral. Corresponderá a la normativa e inspección laboral la prevención y a los servicios sociales la posible corrección a posteriori. Una vez más, la renta básica no puede ser la solución a problemas generales que requieren sus propias políticas.

En sentido inverso, la posibilidad de ofrecer contratos de retribución por debajo de mercado puede servir de incentivo para la oferta de trabajos sociales poco "rentables". Organizaciones con fines de interés social, poco comercial, que no pueden contratar porque los costes salariales de mercado resultan inviables, podrían contar con personas con vocación social que, complementados por la renta básica, más fácilmente podrían aceptar esas condiciones laborales.

Los experimentos realizados hasta el momento coinciden en señalar que una pequeña parte de la población beneficiada opta por reducir su oferta laboral retribuida, en favor de ocupaciones gratuitas o con componente de voluntariado.

También se ha observado un incremento del autoempleo y el emprendimiento. De alguna forma, la renta básica actúa como un impulso inicial de garantía de ingresos hasta tanto la nueva actividad alcance su madurez y rentabilidad esperada.

Desde el mundo sindical se teme que la introducción de la renta básica suponga el abandono de las políticas de pleno empleo, amortiguado el descontento social del desempleo por esta vía. En esa misma línea se mueven las propuestas de empleo garantizado como alternativas a la renta básica. Sin entrar en valoraciones del coste de financiación de unas u otras medidas (aspecto que no se tratará en este artículo), basta con remitir a las reflexiones anteriores sobre los problemas de ligar políticas contra la pobreza y empleo. Y con recordar que la renta básica es necesariamente compatible con otras políticas que actúen sobre las raíces de las desigualdades.

\subsection{VALORES SOCIALES}

Para algunas personas, las dudas sobre la renta básica nacen del mismo concepto. Se cuestionan precisamente la universalidad y la incondicionalidad de la prestación. No puede entenderse que se garantice una renta a cambio de nada y a quien no tiene necesidad de ella. No puede aceptarse una renta garantizada para vagos y ricos.

La renta básica, se dice, erosionaría los valores cívicos y democráticos y dañaría el prestigio de la educación y del esfuerzo; la sociedad perdería la aportación de muchas personas válidas.

Este tipo de temores parte del supuesto, impensable salvo con una renta básica tan generosa que resultaría inviable, de que el efecto reducción de trabajo sería significativo, cuando los indicios resumidos parecen alejar ese peligro.

Respecto a pagar a los vagos, la sensación es que gastamos más dinero y recursos en perseguirlos, con el vano intento de evitar que cobren subsidios, que lo que supondría pagarles la renta básica. Además, como 
dicen Van Parijs y Vandervoght (2017, pág. 139) "la principal inquietud sobre la situación actual no debería ser que algunas personas se salgan con la suya y no trabajen nada sino más bien que innumerables personas que hacen muchísimo trabajo esencial terminan sin tener un ingreso propio".

La postura realista apostaría por subsidiar con una renta básica a esas pocas personas que no desean trabajar, con la ventaja de que dejan sus puestos en el mercado laboral a quienes sí lo desean y serán, con mucha probabilidad, más productivos. Y sin necesidad de organizar un complicado y costoso entramado administrativo de control, a menudo inútil e incentivador de fraudes.

En cuanto al subsidio a los ricos, a quienes no lo necesitan, pueden señalarse algunas reflexiones:

- Actualmente, los ricos reciben ya una renta básica que a nadie parece molestar en el IRPF. El mínimo personal y familiar supone de hecho un subsidio universal para cuantos hacen su declaración de la renta, pues ven reducida automáticamente su cuota tributaria. Parece que se considera justo que se dé a los ricos una cantidad por los gastos mínimos que se suponen de supervivencia. O sea, una renta básica.

- Evidentemente, la implantación de una renta básica supondría algunas medidas complementarias para hacerla financieramente viable. Se suprimirían las prestaciones asistenciales y otras prestaciones y beneficios familiares como el descrito del IRPF. Y, de una forma u otra, se recuperaría parte del gasto en la renta básica a través de alguna forma de mayor presión sobre quienes tienen más capacidad de pago. No estudiaremos aquí las distintas posibilidades. Pero resulta evidente que el resultado final implicaría una mejora para la gran mayoría de la población... a costa de un incremento de la tributación soportada por los más ricos.

Sea cual sea la fórmula, la consecuencia neta es que la renta básica sería percibida íntegramente por las personas y hogares con menor nivel de renta y parcialmente por parte de la población con menor necesidad, con un resultado global nulo o negativo para los de niveles superiores de renta o riqueza. Es decir que, de facto, los ricos no solo no ganarían, sino que perderían con la implantación de una renta básica.

- Además, las situaciones personales son cambiantes. Una persona, una familia, puede encontrarse en una situación económicamente desahogada en un momento y encontrarse en grave situación de necesidad por un cambio repentino en sus condiciones laborales, personales, empresariales... Les excluimos de ayudas porque parecen no necesitarlas, pero cuando llega la necesidad de forma repentina, en vez de recibir ayuda les condenamos a encaminarse al laberinto burocrático con la esperanza de que quizá dentro de un año reciban lo que necesitan. Por ello, la renta básica opta por la ayuda ex ante, y por corregir a posteriori en función de cuál sea la situación efectiva en cada momento.

\subsection{LLAMADA A LA INMIGRACIÓN}

Un temor comprensible y digno de atención iría unido a la posibilidad de que una renta básica indiscriminada pudiera provocar un fuerte efecto llamada de la inmigración, de ciudadanos en situación de pobreza en otros países que se trasladaran a España en busca de una renta segura. Este efecto sería especialmente temible entre ciudadanos con facilidad de movimientos dentro de la Unión Europea.

Evidentemente, las políticas de inmigración son ajenas a la renta básica. Pero sería esconder la cabeza no tener en cuenta este posible efecto. Entre otras razones, porque, de producirse, incrementaría peligrosamente los costes del programa. 
Los estudios sobre movimiento migratorios coinciden en que el efecto llamada fundamental se produce por diferencias llamativas entre el nivel de bienestar entre el lugar de destino y el de origen. JofreMonseny (2013) repasa diversos trabajos que han analizado la incidencia de los programas sociales en los flujos migratorios y la gran mayoría de ellos parecen ratificar que los efectos no suelen ser muy relevantes. Pero hay excepciones que sí encuentran un efecto atracción importante cuando existen diferencias importantes en los beneficios sociales entre países (De Giorgi y Pellizzari, 2009) o regiones colindantes (Fiva, 2009).

Es general la exigencia de algún tiempo de residencia previa para tener derecho. Como señalan Van Parijs y Vandervoght, (2017, pág. 288) no será posible prescindir de alguna versión de estrategia excluyente, aunque suponga la distorsión laboral en la franja de los empleos basura y la injusticia de que personas en igual situación tengan derechos diferentes.

Será muy importante definir adecuadamente cuándo surge el derecho a la prestación. Lo normal será ligarlo a la residencia permanente, que tiene ya unos determinados requisitos y controles previos que evitan un control específico para la renta básica.

Otra conclusión es que la cuantía de la renta, desde esta perspectiva, no debe ser alta si se quiere reducir el peligro de que el incentivo a la migración resulte relevante.

\subsection{EFECTOS COLATERALES}

Son muchos los efectos indirectos que se han ido apuntando a lo largo del amplio debate sobre la renta básica en las últimas décadas. Tanto negativos como positivos.

Uno de ellos, bastante frecuente, es el peligro de provocar una fuerte inflación que, junto a sus efectos negativos habituales, acabaría erosionando el poder adquisitivo de la propia renta básica. Subrayar tal amenaza parece imaginar que la renta básica llega como una lluvia de miles millones de euros que provoca un empujón brutal a la demanda. No será tal. La renta básica sustituirá en buena parte de sus perceptores, a otros subsidios ya existentes y con incrementos de escasa cuantía.

Es cierto que se producirá una redistribución de estratos de población con mayores ingresos a otros con menores. Dado que estos últimos tienen una mayor propensión marginal a consumir, cabe esperar un incremento de la demanda interior, aunque muy inferior al que vaticinan los temerosos del impacto inflacionista. En las circunstancias actuales de la economía, con una clase media menguante y un consumo ralentizado, puede esperarse que los efectos globales sean más beneficiosos que perjudiciales.

Aunque no entraremos aquí en la cuestión de cómo se financiaría la renta básica, es obvio que los recursos que se destinen a este programa tendrán su correspondiente coste de oportunidad. Algunos detractores de la renta básica señalan que mejor sería dedicar esos recursos a otros objetivos como educación o inversiones generadoras de empleo.

En la versión más conservadora (sustituir simplemente los programas actuales) ese coste de oportunidad sería irrelevante porque el cambio equivale a una gestión más eficiente de los mismos recursos.

Pero es probable que la implantación de la renta básica implique alguna dotación adicional respecto a lo que actualmente se dedica a políticas de sostenimiento de rentas. Corresponde a los representantes políticos de la ciudadanía decidir las prioridades. En función de ellas se fijará la cuantía adecuada y, si fuera necesaria, 
la forma de financiar aquello que superase las partidas absorbidas. Pero conviene recordar que en ningún caso la renta básica debe ir en detrimento de las actuales prestaciones del Estado de bienestar y que es necesariamente compatible con otras políticas que persigan el pleno empleo.

Esta es quizás una de las razones por las que, habitualmente, la renta básica no ha despertado especiales simpatías en ambientes sindicales. Los sindicatos apoyan sin problemas programas de rentas mínimas, pero siempre condicionadas y relacionadas con el empleo. Sin embargo, parecen más bien contrarios a una renta básica incondicionada y automática. Puede verse el debate, con temores y ventajas, en Van Parijs y Vandervoght (2017, pgs.226 y ss.), así como en la (más falsa que real) controversia con los defensores del "trabajo garantizado". Sorprenden esas dudas sindicales cuando una renta básica parece fortalecer el poder de negociación, proporciona un fondo de resistencia y favorece la revisión de las condiciones de los trabajos más penosos.

Cabe suponer que las dudas se relacionen con el temor a la desaparición del pleno empleo, o a la puesta en peligro de los sistemas de Estado de bienestar, o a la disminución del propio poder sindical. Pero todos esos temores se relacionan más con la evolución del capitalismo financiero y tecnológico que con la propia renta básica. De hecho, muchos de los recientes defensores de ésta señalan que esa evolución de la economía hace especialmente necesaria la implantación de una renta básica.

Por último, muchas feministas temen que esa renta básica consolide el papel de la mujer encargada de los cuidados y de la casa, al disponer ya de una pequeña renta. También puede encontrarse un resumen del debate en Van Parijs y Vandervoght (2017, pgs.240 y ss.). Evidentemente, el problema de la igualdad de género no va a solucionarse ni con la renta básica ni sin ella, sino por otras acciones y políticas. Pero no es menos cierto que una renta que centra el derecho en las personas y no en las familias, otorga a las mujeres un mayor grado de libertad que cuando se canaliza a través del "cabeza de familia".

Junto a estos temores de costes indirectos, también hay que resaltar los múltiples beneficios colaterales que pueden acompañar a la implantación de un programa de renta básica. Prácticamente todas las experimentaciones coinciden en resaltar una serie de mejoras observadas en las poblaciones afectadas: se estimula la creación de empresas y el autoempleo, disminuyen sustancialmente las tasas de absentismo escolar, se reducen inequívocamente el estrés y las enfermedades sicológicas, desciende la demanda de asistencia médica, bajan también a menudo las tasas de delincuencia... En suma, aumenta sustancialmente el bienestar personal, más allá de los datos meramente económicos.

Es más difícilmente medible, pero es probable que la renta básica favorezca también, a la vista de los efectos observados, una mayor atención a valores diferentes que el puro lucro y el consumo desaforado. Como dicen los autores citados, "una sociedad más libre y una economía sensata".

\section{CONCLUSIONES}

Del análisis efectuado, parece desprenderse que una renta automática e incondicionada que favoreciera fundamentalmente a las personas de menores recursos y en riesgo de exclusión social,y de forma decreciente, al resto de la población, es una política probablemente más eficaz y eficiente para luchar contra la pobreza que la maraña de políticas existentes. Por ello, es recomendable su implementación. Otro tema es su cuantía y financiación, aspectos en los que no se ha entrado en este artículo. 
Podemos concluir con unas recientes palabras de Van Parijs (entrevista publicada en Sin Permiso 07/04/2019): "Para el futuro inmediato, abogamos por una "renta básica parcial", es decir, una renta básica individual, universal y libre de obligaciones... Por encima de este suelo absolutamente seguro, alguna gente tendría derecho a una asistencia social condicionada reforzada, cuyo nivel podría variar a lo largo del país, y también, por supuesto, a las prestaciones de seguros sociales ligadas a los ingresos. No se aboliría la trampa de la pobreza, pero se reduciría de modo significativo. Y la prestación la podría utilizar la gente como subsidio que les ayudara a su empleo asalariado o autoempleo. Pero en términos de poder de negociación y de potencial emancipatorio, hay todo un mundo de diferencia entre una renta modesta a la que tienes derecho pase lo que pase y otra a lo que tú o tu patrón sólo tenéis derecho si aceptas que te metan en un trabajo repugnante, y que pierdes si decides dejarlo". 


\section{REFERENCIAS BIBLIOGRÁFICAS}

- Arriba, A. y Ayala, L. (2013): "El sistema de garantía de ingresos: tendencias y factores de cambio", Presupuesto y Gasto Público, 71/2013. Págs. 259-276.

- Ayala, L. y Gimeno, J. A. (2019): Un Estado de bienestar para el siglo XXI. IEF (en prensa)

- Ben-Shalom, Y.; Moffitt, R.A. y Scholz, J.K. (2011): An Assessment of the Effectiveness of Anti-Poverty Programs in the United States. NBER Working Paper No. 17042.

- Bollain, J. y Raventós, D. (2019): "La Renta Básica Incondicional ante las limitaciones de las Rentas Mínimas". SIN PERMISO. 04/01/2019.

- CES (Consejo Económico y Social) (2017): Políticas públicas para combatir la pobreza en España. Informe 01/2017.

- Comisión Europa (2019): The Impact of the Digital Transformation on EU Labour Markets. Report of the highlevel expert group. European Commission. Brussels

- Danziger, S.; Haveman, R. y Plotnick, R. (1981): How income transfers programs affect work, savings and the income distribution: a critical review. Journal of Economic Literature, n. 19, págs. 975-1028.

- De Giorgi, G. y Pellizzari, M. (2009): Welfare migration in Europe, Labor Economics 16, pp. 353-363.

- European Social Survey (2016) - Noguera J.A. EL PAÍs: 9/02/2019.

- FIVA, J.H. (2009), Does welfare policy affect residential choices? An empirical investigation accounting for policy endogeneity. Journal of Public Economics, n. 93, pp. 529-540.

- Jofre-Monseny, J. (2013): The effects of unemployment benefits on migration in lagging regions. Document de treball de l'IEB 2013/10. Institut d'Economia de Barcelona.

- Laparra, M. y Ayala, L. (2009): El Sistema de Garantía de Ingresos Mínimos en España y la respuesta urgente que requiere la crisis social. Fundación FOESSA. Madrid.

- Llano Ortiz, J. C. (2018): El estado de la pobreza: seguimiento del indicador de pobreza y exclusión social en España 2008-2017. (Informe AROPE). EAPN.

- Malgesini Rey, G. (2014): Informe sobre los Sistemas de Rentas Mínimas en España. COMISIÓN EUROPEA Dirección General para el Empleo, los Asuntos Sociales y la Inclusión. EAPN ESPAÑA.

- Muñoz de Bustillo, R. y Antón, J.I. (2013): Mercado de trabajo y demanda de protección social. Presupuesto y Gasto Público. 71-2/2013, pp. 101-126.

- Peña-Miguel, N. y De la Peña Esteban, J. I. (2014): Hacia una Prestación Social Básica en un Estado de Bienestar. Lan Harremanak. 2014-II. Págs. 16-35.

- Sanzo González, L. (2018). La política de garantía de ingresos en España. ZERBITZUAN 65. Mayo 2018. Págs. 41-51.

- Uribarri, I. (2015): No es una buena idea extender el sistema de rentas mínimas condicionadas de Euskadi al conjunto del Reino de España. SIN PERMISO. 08/11/2015.

- Van Parijs, P. y Vandervoght, Y. (2017): Ingreso básico. Grano de Sal. México. 


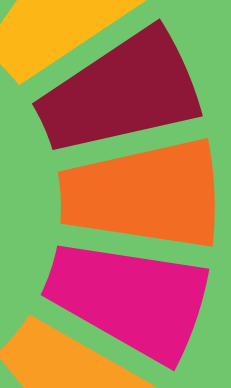

\title{
LA JUSTIFICACIÓN NORMATIVA
} DE LA RENTA BÁSICA UNIVERSAL DESDE LA FILOSOFIAA POLÍTICA Y EL DERECHO

\section{THE LEGAL AND PHILOSOPHICAL GROUNDS OF THE UNIVERSAL BASIC INCOME PROPOSAL}

\author{
Borja Barragué \\ Ministerio de Sanidad, Consumo y Bienestar Social \\ borja.barrague@uam.es \\ Luis Arroyo Jiménez \\ Universidad de Castilla-La Mancha \\ luis.arroyo@uclm.es \\ Mª Celia Fernández Aller \\ Universidad Politécnica de Madrid \\ mariacelia.fernandez@upm.es
}

Fecha recepción artículo: 13/08/2019 • Fecha aprobación: 18/09/2019

\section{RESUMEN:}

En este trabajo se analizan diversas razones que, procedentes de la filosofía política y el Derecho positivo, pueden justificar el establecimiento de una renta básica universal. En primer lugar se ofrece una visión panorámica de la justificación normativa de la renta básica universal, distinguiendo tres modelos que responden a otras tantas concepciones de la justicia social. El artículo se centra a continuación en argumentos que proceden del orden jurídico positivo (internacional, europeo e interno) y que pueden adquirir relevancia en la discusión acerca del establecimiento de una renta básica universal y, en particular, acerca de sus fortalezas o debilidades frente a otras medidas cercanas como, por ejemplo, las rentas mínimas de inserción.

Palabras clave: Renta básica universal, rentas mínimas, Derecho internacional, pilar europeo, Estado social, democracia, renta mínima de inserción.

\section{ABSTRACT:}

This paper analyzes various reasons coming from political philosophy and positive law, which can justify the establishment of a universal basic income. First, a panoramic view of the normative justification of universal basic income is offered: three models that respond to many other conceptions of social justice are presented. The article then focuses on arguments that come from positive legislation (international, european and domestic law) and which can become relevant in the discussion about the establishment of a universal basic income and, precisely, about its strengths or weaknesses against other quite similar measures such as minimum insertion income.

Keywords: Universal basic income, International Law, European Pilar, Social State, Democracy, minimum insertion income. 